\title{
Osteoporosis Patients with Fall-Related Injuries in Residential Environments: Challenges for Social Work
}

\author{
Jörgen Lundälv \\ Department of Social Work, University of Gothenburg \\ Sprängkullsgatan 23
}

PO Box 720, SE 40530 Gothenburg

E-mail: Jorgen.Lundalv@socwork.gu.se

Received: January 10, 2018 Accepted: February 14, 2018 Published: February 16, 2018

doi:10.5296/ijsw.v5i1.12675 URL: http://doi.org/10.5296/ijsw.v5il.12675

\begin{abstract}
The study describes the osteoporosis patient's need of support from medical social workers because of risks and injury events in residential environments. The study includes qualitative interviews of patients and a survey of medical social worker visibility in the media. Findings show that patients feel a lack of knowledge, recognition, and moral respect from the environment. Support from a medical social worker is significant, and activation in a patient association and an osteoporosis school is seen as employing valuable information channels. However, these have a fairly limited visibility in the media, when it comes to describing support opportunities and preventive work.
\end{abstract}

Keywords: Osteoporosis, Injury events, Residential environments, Recognition, Medical social worker, Axel Honneth, Sweden

\section{Introduction}

The chronic women's disease osteoporosis affects people around the world. In a well-developed democracy like Sweden's, with a variety of professions in that area, the "osteoporosis problem" should be an established theme at both the general level, for example, in media coverage and public debates, as well as the structural one, for example, as laws and ordinances (Social Services Act, 2001). However, in social work, research shows how these osteoporosis problems, well known among those concerned, have difficulty gaining sufficient attention and weight in terms of supportive regulatory systems or legislation. An increasingly 


\section{Macrothink}

International Journal of Social Work

ISSN 2332-7278

2018, Vol. 5, No. 1

aging population in Sweden as well as in many other European countries will increase demands on supportive measures for older people diagnosed with osteoporosis (SBU, 2017). The number of injury events affecting this patient group is unlikely to decrease in residential environments without active injury prevention and support. These are major challenges in social work, not least given the role and work of the medical social worker at individual and group levels but also at the society level (Hobbs, 2005).

In Sweden, a total of 500000 people are affected by osteoporosis. The National Board of Health and Welfare's National Guidelines state that the goal is for $30 \%$ of all patients to receive treatment. Each year 60000 fractures occur in Sweden that are related to the disease. The total annual cost of fractures amounts to SEK 12.5 billion (total social cost). In Sweden, the Osteoporosis Association, a patient organization, has been given financial resources to launch several so-called osteoporosis schools since 1995. Development in this area is important and has a high relevance for social work and especially medical social work in health care. It is estimated that there are a total of 5100 medical social workers throughout the health care sector in Sweden, and it has also been decided that this profession group will receive a credential (The National Board of Health and Welfare, 2014; Government Offices of Sweden, 2017). In social work, the Social Services Act (2001) is responsible for, among other things, elderly care, health care legislation, and the Act on support and services for some people with disabilities (Swedish Code of Statutes SFS 1993:387, Act on Support and Services for Persons with Certain Functional Impairments).

So, what has happened since researchers Munch and Shapiro (2006) published their article in Social Work in Health Care about the importance of social work and the importance of prevention work? In Sweden there are several so-called osteoporosis multidisciplinary teams in the health care sector. Here, several professions, including medical doctors, nurses, physiotherapists, and occupational therapists, work in teams to provide treatment, advice, and support. There are also several so-called osteoporosis schools in Sweden that provide information and education in smaller groups of patients. In an American study on social work and osteoporosis, the researchers are focusing on possible interventions concerning prevention in social work. They describe primary, secondary, and tertiary disease prevention that social workers in health care can perform from outside (Munch \& Shapiro, 2006). However, (a decade ago) the researchers found only two articles on the subject published in social work journals (Roberto \& Johnston, 1991; Kinderknecht, 1992). This is surprising, given that social workers in health care have several important tasks to fulfill. In primary prevention, the medical social worker can help inform patients about the disease and provide new knowledge about support opportunities. At this level of society, the medical social worker can work preventively and, for example, participate in higher education in social work at the university when it comes to knowledge of osteoporosis. Secondary prevention involves the medical social worker supporting patients and family members in their coping and living conditions. The medical social worker can also encourage patients in their relationships and communication with other professions in health care. Tertiary prevention may mean the medical social worker, for example, offers home-based support for the patient who requires a housing adaptation or use of aids, or organizes training activities (Munch \& Shapiro, 2006).

Nonetheless, international medical-oriented research on osteoporosis reveals consequences of 
osteoporosis in everyday life for social living conditions, quality of life, and well-being (Koleck et al., 2006; Wilson et al., 2012; Kristensen et al., 2017). Patient awareness and prevention efforts have also been highlighted in that kind of literature (Jensen et al., 2016; Harvey et al., 2017). Women's vulnerability to the disease has been the focus of several long-term studies (Gold, 1996; Blakeley et al., 2000; Curry et al., 2002; Chan \& Ko, 2005; Svejme, 2013). Studies have also focused on the disease in elderly people (Svensson et al., 2016; Svensson et al., 2017). The importance of social support from the social network has been described in the research (Ranby \& Aiken, 2016). The media as an important information channel for health care professions has been highlighted in an Australian study (Sambrook et al., 2010). It has given rise to an interesting conclusion, namely, that reporting can cause more harm than patient benefit (Sambrook et al., 2010). The reason should be that media coverage does not always present a balanced view of, for example, risks of medication for patients. On the other hand, there is limited research on how social workers in health care use the media to reach the community with preventive work and information.

\section{Purpose of the Study}

The purpose of the study is to explore patients' experiences of osteoporosis concerning risks and injury events, and of social support in residential environments, and (to study) to what extent patients perceive that these experiences have been acknowledged by the environment (professional representatives and family members). The purpose is also to study to what extent these experiences are reflected or recognized in the general picture of the bone disease osteoporosis, as depicted in the media coverage during 1998-2016. The investigation is done from a Swedish social work perspective, and the media coverage is limited to Swedish print news media. This means that the study examines whether the patients consider themselves to have received social recognition for these everyday life-related problems in their residential environments (that arise in the course of the disease) and how professionals, in this case social workers in the medical field, so-called medical social workers, actualize these experiences in the media.

\section{Theoretical Perspective}

Central to the theoretical perspective applied in the study is the concept of recognition, related to the individual - the patient - as well as to the social services, in their so-called general and structural levels, which will be combined here with the theoretical concept of public sphere. Both concepts, recognition and public sphere, are central to the German social philosopher Axel Honneth in his analysis of respect for the individual's need for freedom and participation in the society (Honneth, 1995; 2014). With the concept social recognition, he refers to a communicative interaction between individuals, characterized by reciprocity. The theory of social recognition includes the following three personal characteristics: self-confidence, self-respect, and self-esteem. If a person is to be recognized as a human, she must be recognized in every aspect of self-confidence, self-respect, and self-esteem (Honneth, 1995). Inspired by colleague Jürgen Habermas, reciprocity gives a moral dimension based on respect for each other's right to express one's opinions freely and without reprisals, a process strengthening self-determination as well as self-realization. A refused recognition can create feelings of being morally offended (Honneth, 1995). This can happen if, for example, the individual's safety with regard to physical well-being is overridden, as in cases of abuse, 
torture, or rape, which destroys trust. But even if one disagrees with the moral tolerance of the individual, questionability is questioned, such as when fraud is alleged fraud when an entire group becomes legally deprived, which destroys self-esteem. Feelings of violation may also occur if one is humiliated, for example, in not only fairly harmless behaviors like failing to greet a person but also more coarse behavior like directly labeling and stigmatizing someone, which harms the feeling of being socially important in a concrete community (Honneth, 1995). Compared with a more pure system-oriented sphere, for example, where decisions about citizenship and enforcement of laws take place, the latter are more focused on justice. These different levels are described by Honneth as a fairness aspect and a solidarity aspect. He thus calls the first the recognition of justice and the second social recognition. In addition to these, he also identifies a kind of recognition linked to private relationships, which he calls personal recognition. Honneth also argues for autonomy:

Autonomy is a relational intersubjective entity, not a monological achievement. What helps us to acquire autonomy is not cut out of the same cloth as a good that can be distributed; it is fashioned out of living relations of reciprocal recognition that are just to the degree that they allow us to reciprocally value our needs, beliefs and abilities. (Honneth, 2012, p.41)

This links the concepts to Habermas's discussion of private autonomy and collective autonomy, which he claims are equally important for the individual. When, for example, marginalized groups require recognition, it is important that they both express their own experiences and gain recognition in the public domain. The members of a community expect equality of treatment, that is, "each one treats everyone else as" one of us. "In this sense, justice means solidarity at the same time" (Habermas, 2008, p.217). Habermas said:

Equal respect for everyone is not limited to those who are like us; it extends to the person of the other in his or her otherness. And solidarity with the other as one of us refers to the flexible "we" of a community that resists all substantive determinations and extends its permeable boundaries ever further. This moral community constitutes itself solely by way of the negative idea of abolishing discrimination and harm and of extending relations of mutual recognition to include marginalized men and women. (Habermas, 2008, p.xxxvi)

For patients with osteoporosis problems, it means the desire for a relationship that is based on the feeling of being seen, both by people in their vicinity and also by the professionals they encounter in everyday life, such as the nurse, medical doctor, or medical social worker in health care, as representatives of the public sphere. Recognizing the patient's own experience and knowledge of his problem, gives energy to handle it in a more constructive way. The term social sphere is here matched with Honneth's public sphere (Honneth, 2014). By that, he means a sphere where democratic rights are given free space, for example, via discussion in the media, voting, or generally speaking in debates, conversations, and so forth. Characteristic of the sphere is its starting point in an intersubjective interaction, such as thus making it possible to show solidarity. Honneth said:

In order for us to be free to base our actions on principles we view as right, we must be viewed by our communication partners as capable of controlling our intentions through 


\section{Ml Macrothink}

International Journal of Social Work

ISSN 2332-7278

2018, Vol. 5, No. 1

higher-order acts of will and of obeying 'which I will term 'moral respect', is the fact that it combines the respect for the irreplaceable individual with the latter's involvement in the community of humans, thus joining individuality to universality. By viewing individuals as normatively capable of justifying the reasons for their actions to others, we also permit them to articulate only those principles that they themselves view as right. (Honneth, 2014, p. 106)

Honneth's use of the terms recognition and moral respect indicates a relationship between two people (here, between patient and professor, medical social worker, etc.) and implies that there is a reciprocity in this relationship that is built on trust (Honneth, 1995; Honneth, 2014). If a patient with osteoporosis experiences that she is seen and confirmed by, for example, a nurse, medical doctor, or medical social worker in the health care system, recognition is given to her experience, knowledge, and situation. A rejected acknowledgment may, on the other hand, occur when one is not confirmed or even unable to get help, even in a vulnerable life situation. This lack of intersubjectivity will influence the building of identity and the process of further interaction, two aspects highlighted in the study. Honneth describes the "struggle for recognition" as a process to achieve a personal identity, which, for example, a professional in health care or a medical social worker can support. A refused recognition means that the individual has to put extra energy into being accepted, which can be too much with respect to everything else an exposed person may have to handle. According to Honneth, there are three types of recognition, having individual, legal, and value dimensions (Honneth, 2004).

This study focuses only on the individual and the value dimensions because the study is conducted in Sweden, where the individual's rights are already contained in legislation. In Sweden there are three important laws in the area: The Social Services Act, The Act concerning Support and Service for Persons with Certain Functional Impairment and the Act on housing adaptation. This is in line with Honneth's argumentation when he said, "then the moral quality of this social integration can improve through an increase either in the 'recognized' personality portions or in the involvement of individuals - briefly, through individualization or through growing inclusion" (Honneth, 2004). This study is concerned with two types of recognition: (1) legal recognition (social rights accompanying citizenship in a welfare system), and (2) social recognition (social appreciation and self-esteem). Legal recognition can be understood as the more definitive confirmation that a problem has been accepted in the welfare system. It thus confirms that there are already rights in the welfare system and that they are regulated in legislation. Important in this context, however, is that legal recognition means that the individual has already been facing the problems socially.

Since the focus of this study is social recognition, it will be applied in relation to vulnerable groups. The perspective clarifies how weak groups conduct a struggle for recognition that deals with existence and independence, for example, in the interaction between the patient and the medical social worker. The result could be that individuals and groups attempt to highlight positive views and strengths and try to achieve change through participating in the public debate. Honneth emphasizes in particular the vulnerable groups' ability to participate in the social debate (Honneth, 2014). A patient, patient organization, or medical social worker can then take an active role in opinion formation in society, as Honneth discussed (Honneth, 2014). Analogous to that, a medical social worker can find support in the Social Services Act to 
participate in preventive work at the community level. For the patient, patient organization, or medical social worker, this social sphere, the public sphere, can be a space where these different solidarity processes can happen. The Social Services Act in Sweden specifically supports this, thereby empowering the Osteoporosis Association and medical social workers to share their experience and knowledge of patients with osteoporosis in the public sphere. Here the medical social worker plays an important role in social work at the community level.

\section{Methods}

The present study has been conducted in southern Sweden (Västra Götaland County). It includes two types of material: Qualitative interviews with a total of 10 women diagnosed with the bone diseases osteoporosis were conducted during the period February to April 2017. As well, a quantitative material consisting of published news articles in the media was selected by the Osteoporosis Association, which is a national patient association. This means that the participants have a connection with the patient association. There were no specific selection criteria set. The study was approved by the Ethical Review Board in Sweden in 2016 (No. 366-16). Interviewees provided written consent to participate in the survey. The researcher also gave participants oral information about the research project. Interviewees also agreed to have the interviews tape recorded. The interviews were subsequently transcribed and analyzed using qualitative content analysis. The results were analyzed based on Axel Honneth's theory of recognition and on the recognition forms. Interviewees are anonymized in the article. A data collection from the Retriever database Mediearkivet was also made of published news articles in news media in Sweden during the 19 years from 1998 to 2016. The time embargo for the literature search (news media) was chosen because there was a limited number of news article in the Mediearkivet database before 1998. By studying the period 1998-2016, a good overview of the publications for almost two decades was achieved.

The news media consist of national and local news print media. Keywords used to search for material were osteoporosis, osteoporosis teams, osteoporosis school, and medical social worker. A total of 74 news items were found during the period (osteoporosis school, 37 articles; osteoporosis teams, 26 articles; and medical social worker, 11 articles). In total, there were 1326 news articles published dealing with the disease osteoporosis in the media during the period.

\section{Results}

The article presents the empirical findings and results from the survey as a two-step result. The first step consists of an account of the interviewees' experiences of risks, injuries, support, and the various acknowledgments they received for them from the hospital care and support system. In the second step, the general picture of the news media's reporting on the disease osteoporosis is presented briefly. The article concludes by discussing and summarizing the outcomes concerning experiences of the participants and their feelings of recognition, and then connecting them to the outcome of the dialogical relationship between patient and medical social worker. Finally, an overall question can be addressed: how much of the patients' problems connected to osteoporosis are reflected or depicted in the media picture, or by professionals, especially the medical social workers in Sweden, and what kind of challenges can be described? In 2017 a total of 10 participants who had been diagnosed with osteoporosis were interviewed. All of them were women between the ages of 57 and 90 years and resident in 
southern part of Sweden. Half of the participants were living without any partner, while half of them were living with a partner. All participants had families with children. Half lived in apartments (rental apartment or condominium) and others lived in a detached home or townhouse. Several of the patients had participated in a so-called osteoporosis school where they had gained knowledge and awareness of not only risks and injury events but also injury prevention. Only one participant used any aids or equipment in daily life. Four of the participants had experience of injury events at home. All six injury events had occurred in residential environments. Five injury events had occurred inside the home in the kitchen, hall, bedroom, or balcony. Half of the participants had received hospital care. Common for the participants was that they felt worried about being injured by falling at home. Fear of falling had made them more cautious when moving about indoors and outdoors. The residential environment was important to all the patients, and they reported on how they felt both safe and unsafe. A woman described her situation:

The "living" room. It's a bit my room. I live there. There we have our dining table. There I have my place at the window. There I sit a lot and read or ... I have the computer there. I eat there or have a meal or sit and hang out. (female, 57 years)

A woman described an injury event that occurred in the bedroom. She said:

It's always when it's in a hurry that it happens. I open the closet door and take what I want. Spin around a bit too fast so I fall and lie on the side instead. I did not break anything. It's the first [reaction] to feel that you have not broken anything. And then you will eventually get up and then you will calm down a bit. You always get a little scared. (female, 83 years)

Another woman described an injury event. She said:

I've fallen once and hit my leg. Had bought a new table. It was a low table and I had a high chair and had programmed it to be so high. It had no handle so I fell sideways. I should have thought of that. (female, 82 years)

To prevent injuries, several of the patients suggested not having any carpets on the floor and not having a home that is over-furnished. It is also important that it is clean and there are no items on the floor to trip over. The possibility of being able to safely evacuate from the residence in a fire is also important.

\subsection{Social Recognition}

Social recognition can be obtained when women meet others in similar situations, for example, in a patient association or at an osteoporosis school located in the hospital. But even if there is an opportunity to share experiences about risks, injuries, and safety in the residential environments, not all people want it. A participant said:

Not something special. Just at the "osteoporosis meetings," but not that I've been telling anything much about myself... I do not go very much to these meetings, but I go if it's a good speaker". (female, 90 years).

A patient described the significance of the patient association and the information she received about risks and preventive work in the home. She said:

It is thanks to this Osteoporosis Association that I have received much help. Before I was not included. That's when I broke my wrist. Before that, I absolutely did not think so. 
(female 70 years)

Patients are entitled to receive support and assistance in processing and rehabilitation and, for example, preventive work in the home. A woman described the disease and her life situation:

I have not accepted that I have an injury. I cannot think so mentally. (female, 68 years)

One result shows that it is important to find out which rights one has, for example, the right to have housing adaptation in the apartment or to tell whether you need an aid to manage your daily routine. The social network also has a great importance in support of concerns about injury events in the residential environment. A woman related that her daughter worried about her in the residential environment. She said:

She's worried that I'm going to slip. My daughter wants my last one to take a close look at me, for her sake. (female, 65 years)

A woman ( 82 years) believed that it is not just about rights but also about the individual's obligations to learn about risks, safety, and prevention itself. Her own responsibility is important, she said:

One will find out a bit, but it is not so popular today. One should get everything served best. It is the case with the individual. Everyone is responsible for it, but it is not entirely clear. You are talking very little about the obligations. (female, 82 years)

\subsection{Offenses and Disrespect}

Some of the interviewees were perplexed by their surroundings. Lack of moral respect occurs, for example, in meetings with others in similar situations or in contact with the health care services. All the participants considered it important to have information and education about risks in residential environments, but also experienced a lack of information available in society. A patient described the hopelessness. She said:

All enlightenment is good. It's a lot of tips to make it easier for you to use simple means.

It's not certain that you need to have big stuff without... It's just that there's no help to get. (female, 90 years).

The participants continued to describe a form of lack of moral respect:

You need to meet people but... I do not like talking about diseases directly. I would rather go on things that are not disease-related. Obviously, if you can exchange it, I think it's very boring when they start talking about their illnesses and pull up the entire medical record. Then I'm going. (female, 90 years).

One of the participants (female, 68 years) said she had visited the health center and tried to leave brochures and newspapers from the Osteoporosis Association, but she was not allowed to leave such material there. She has not received any justification as to why they would not accept the material. She recalled that she met a staff member who said, "Think if all associations were to leave material here. How would it look?" A participant said that the role of the medical social worker is important in the field of health care and that she herself wanted to meet a medical social worker. There could also be a special coordinator who could provide information about risks, support, and design of a safer residential environment. (female, 68 years) She said:

There must be someone who can guide me and who is in possession of a knowledge bank. 


\section{1) Macrothink}

International Journal of Social Work

ISSN 2332-7278

2018, Vol. 5, No. 1

No one has said anything to me... but where should I turn? Send me to the medical social worker! Then he could tell me that you can do this. Where can I get into to help me get a better environment? (female, 68 years).

To prevent fall-related injuries, it is important to have foot care and good shoes indoors. An 80-year-old patient explained what experiences she herself had with wearing shoes in the home and taking care of her feet to avoid risks and injury events. She had told this to health care professionals, but experienced that she was not taken seriously. She said:

I've tried to pay attention to this with my feet. "Yes, they say. You're right about that." But nobody does anything. I think it's a social problem. (female, 84 years)

Several of the participants in the study found that in the field of health care professionals do not always listen to the patients about their experiences and vulnerabilities. The participants have to a limited extent received legal and social recognition for their experiences of risks, injuries, and unsafe conditions in the residential environment. In some cases, women have experienced problems with lack of moral respect shown in both treatment and action in the field of health care. Based on Honneth's theory of recognition, the women have not resigned, but are still active and committed to the patient association. They also talked about good experiences from the osteoporosis school at the hospital. Women want to share experiences with others and have attention paid to risks and injury events in the residential environment as a major social problem.

\subsection{Media Coverage}

The visibility and role of the medical social worker in prevention work on osteoporosis has been reported in various ways in the media report. The result of the search in the Retriever database Mediearkivet shows partly how the media have reported but also how visible the medical social worker is in the media, and tells about medical social work, osteoporosis, and prevention. Figure 1 show the media coverage in 19 years in Sweden.

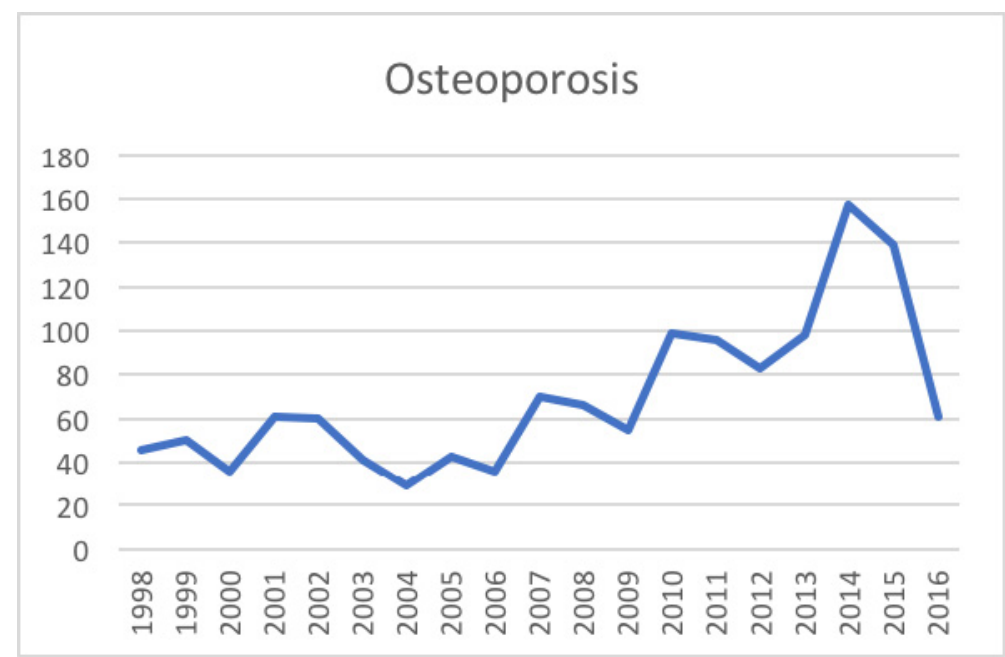

Figure 1. The general picture of osteoporosis in Sweden, indicated by the media coverage during 1998-2016. News articles about osteoporosis in Swedish newspapers $(\mathrm{N}=1326)$. Absolute numbers are shown. Source: The Retriever database Mediearkivet. 


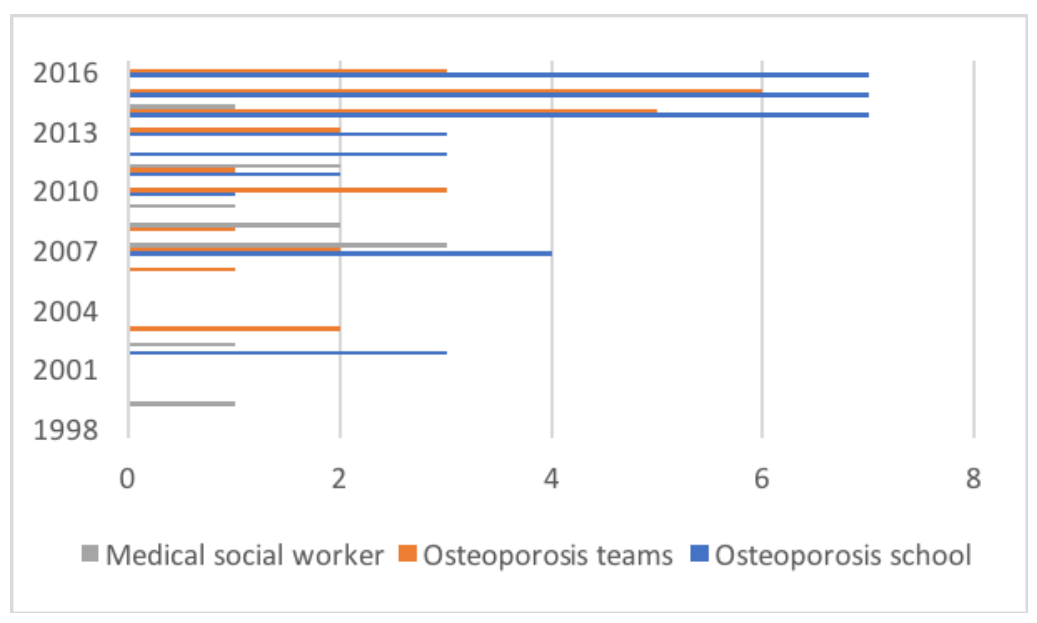

Figure 2. Prevalence of news about osteoporosis schools, osteoporosis teams, and the role of the medical social worker, indicated by media coverage during 1998-2016. News articles in the Swedish newspapers $(\mathrm{N}=37)$. Absolute numbers are shown. Source: The Retriever database Mediearkivet.

Figure 2 shows that during the period a total of 37 articles were published in the news media describing the osteoporosis school and its function, while 26 articles described the special osteoporosis multidisciplinary teams in the health care sector. In 11 articles the role of the medical social worker was differentiated in relation to the disease osteoporosis. In these articles there are only a few in which a medical social worker is interviewed and tells about social support, preventive work, or teamwork with other professions in health care. The visibility of the medical social workers in the media coverage in Sweden during the period can be seen as quite limited. None of the articles focus on patient risk exposure or experience of injuries in residential environments. In the media coverage representatives from patient associations also have written opinion articles to highlight the importance of support efforts for patients with osteoporosis. The results of the study show that the Osteoporosis Association as a patient organization is active in the news media and in recent years has participated in opinion articles on the situation of patients in society. However, despite a few debates, there has not been a major social debate in Sweden. The medical social worker is not involved in the public debate at all.

\section{Discussion}

The main findings in the study show that there is a high level of vulnerability for women with osteoporosis and that they have difficulties in receiving social recognition from the society. The study has shown that it is important that the patients be recognized for their experiences of both the disease and the injury events they suffer from in residential environments. The study has also shown that these patients have high insight and important knowledge about how to prevent injury events in residential environments. Anxiety for injury events through cases in the home is something that is recurring with the participants. This type of reaction has also highlighted previous research (Svensson et al., 2016). The study shows that almost half of the patients have experienced injury events themselves at home, but the anxiety is frequent. The injuries that arise are about twisting of wrists and fractures. The injury events have taken place in different 
rooms in the residential environments. The participants have a high awareness of risks and risk situations, as evidenced, for example, by often avoiding standing on chairs or ladders. They have also reduced the pace of movement indoors and take more time getting around. Lack of contacts with a medical social worker emerged in the study. The media can be an important forum for several professionals in health care when it comes to the safety and security of the osteoporosis patients in residential environments. The forum may be particularly interesting also for medical social workers because they have or are expected to have more or less extensive dialogue and communication with the patient.

This study has several limitations. One limitation is that only women diagnosed with the bone diseases osteoporosis participated. This may have several explanations. One explanation is that more women than men are affected by osteoporosis. In the study, however, the explanation may be that the sample was random and that there are many people who are not members of a patient association in Sweden and therefore have not been included in the sample. From a gender perspective, it may be interesting in further studies to include men who suffer from the disease. It has not been the purpose of the study to make comparisons between how women and men experience their situations. Another limitation of the study is that it focused solely on people who live in the southern part of Sweden. There are people who live in other parts of the country and in rural areas. The problem with rural areas may be that there are relatively long distances to access health care and social services. Further research could also focus on patients with osteoporosis in rural areas.

Several of the interviewees have participated in a so-called osteoporosis school and even been active in a patient association where there is also knowledge about the disease, treatments, rehabilitation, equipment, and awareness concerning risk factors in the residential environments that may be of significance for an injury event. But what happens when the patient has finished the osteoporosis school or becomes less involved in the patient association for various reasons? Who listens to the person's experiences of an injury that has occurred in the residential environment? What experiences do patients have from their family members and close relatives? These questions are important to reflect on. Here, for example, a medical social worker could conduct follow-up talks or, in conjunction with an occupational therapist, make home visits to the person. The traditional media (press, radio, and television) as a forum for the medical social worker to be more involved in advocacy and preventive action against injuries and to participate in social planning may be good and provide several benefits, as patients usually consist of older people who may lack familiarity with or be unaccustomed to using social media like Facebook, Twitter, and so on. Otherwise, there is a risk of a lock-in effect, namely, that large patient groups of elderly people are not reached by important information on rehabilitation and social support. For the patient's life situation, safety, and opportunities to work more with injury prevention in the residential environment with the disease, the medical social worker can be an important resource for social support. For the medical social worker to provide support, he or she needs knowledge of the patient group and the disease. In Sweden, a new higher education for health care practitioners can create good conditions for strengthening social work for this patient group (The National Board of Health and Welfare, 2014; Government Offices of Sweden, 2017). It is important that medical social workers receive more education about chronic diseases, pain, and aches. It is also important 
that the medical social worker is a natural part of the transdisciplinary team, available to meet and work with other professions. The study has shown that there are physicians as well as representatives from patient organizations who have written opinion articles in the media. On the other hand, the voice of the trustee is not present in the public debate. There are also examples of patients who joined a group and formed their own association and reported on this work in the media. It is important also for other reasons that medical social workers in the future become more active at the social level and demonstrate their profession and role.

From an osteoporosis perspective, the competence and experience of the medical social worker is important for communicating with patients, relatives, and other professionals in health care. To summarize the findings of the study, it is important to conclude with the following words. It is important that patients' recognition should be strengthened and that awareness be raised about their needs in the welfare society. The medical social worker is in a unique position in being able both to maintain intersubjective communication and also to convey knowledge and awareness in the public sphere. Finally, the depiction by the media of the disease osteoporosis, injury events, and prevention can be more nuanced and comprehensive in terms of the medical social workers', patients' and relatives' voices. In this way, legal and social recognition can also increase.

\section{Acknowledgment}

Thanks go to the participants in the study who contributed with their experiences. Thanks to Anita Kihlström, Associate Professor of Social Work at the University of Gothenburg, who provided valuable views on the manuscript. Thanks are due to the Swedish Civil Contingencies Agency (MSB) for funding the study, as well as to the members of the research group at Chalmers University of Technology in Gothenburg, Sweden.

\section{References}

Blakeley, J., Laryea, M., \& Ribeiro, V. (2000). Women's knowledge and practices regarding the prevention and treatment of osteoporosis. Health Care for Women International, 21, 347-353. https://doi.org/10.1080/073993300245195

Chan, F. M., \& Ko, Y. C. (2005). Osteoporosis prevention education programme for women. $\begin{array}{llll}\text { Journal of Advanced } & \text { Nursing, } & \text { 54(2), } & \text { 159-170. }\end{array}$ https://doi.org/10.1111/j.1365-2648.2006.03804.x

Curry, C. L., Hogstel, O. M., Davis, C. G., \& Frable, J. P. (2002). Population-based osteoporosis education for older women. Public Health Nursing, 19(6), 460-469. https://doi.org/10.1046/j.1525-1446.2002.19607.x

Gold, D. T. (1996). The clinical impact of vertebral fractures: Quality of life in women with osteoporosis. Bone, 18(1), S185-S189. https://doi.org/10.1016/8756-3282(95)00500-5

Government Offices of Sweden. (2017). Legitimation för hälso- och sjukvårdskuratorer. Ds 2017:39. Stockholm: Government Offices of Sweden.

Habermas, J. (2008). The inclusion of the other: Studies in political theory. Cambridge, MA: MIT Press.

Harvey, N. C. W., McCloskey, E. V., Michell, P. J., Dawon-Hughes, B., Pierroz, D. D., Reginster, J.-Y., Rizzoli, R., Cooper, C., \& Kanis, J. A. (2017). Mind the (treatment) gap: A global perspective on current and future strategies for prevention of fragility fractures. 
Osteoporosis International, 28(5), 1507-1529. https://doi.org/10.1007/s00198-016-3894-y

Hobbs, M. D. (2005). The social worker on the medical transdisciplinary team. Journal of Health Care for the Poor and Underserved, 16(2), 186-191. https://doi.org/10.1353/hpu.2005.0035

Honneth, A. (1995). Struggle for recognition: The moral grammar of social conflicts. Cambridge, UK: Polity Press.

Honneth, A. (2004). Recognition and justice: Outline of a plural theory of justice. Acta Sociologica, 47(4), 351-364. https://doi.org/10.1177/0001699304048668

Honneth, A. (2012). The I in we: Studies in the theory of recognition. Cambridge, UK: Polity. Honneth, A. (2014). Freedom's right: The social foundations of democratic life. New York, NY: Columbia University Press. https://doi.org/10.7312/honn16246

Jensen, A. L., Lomborg, K., Langdahl, B. L., \& Wind, G. (2016). Managing a bone healthy lifestyle after attending multifaceted group education. Calcified Tissue International, 99, 272-281. https://doi.org/10.1007/s00223-016-0147-1

Kinderknecht, C. H. (1992). Social work with the osteoporotic woman. Journal of Women \& Aging, 4, 57-76. https://doi.org/10.1300/J074v04n01_05

Koleck, M., Mazaux, J.-M., Rascale, N., \& Bruchon-Schweitzer, M. (2006). Psycho-social factors and coping strategies as predictors of chronic evolution and quality of life in patients with low back pain: A prospective study. European Journal of Pain, 10(1), 1-11. https://doi.org/10.1016/j.ejpain.2005.01.003

Kristensen, P. K., Thillemann, T. M., Pedersen, A. A., Søballe, K., \& Johnsen, S. P. (2017). Socioeconomic inequality in clinical outcome among hip fracture patients: A nationwide

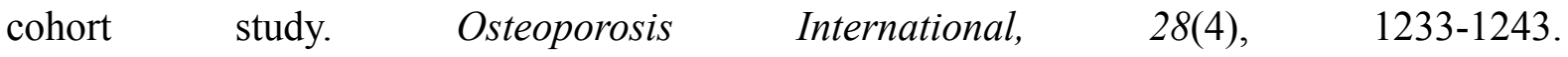
https://doi.org/10.1007/s00198-016-3853-7

Munch, S., \& Shapiro, S. (2006). The silent thief: Osteoporosis and women's health care across the life span. Health \& Social Work, 31(1), 44-53. https://doi.org/10.1093/hsw/31.1.44 Ranby, K. W., \& Aiken, L. S. (2016). Incorporating husband influences into a model of physical activity among older women. British Journal of Health Psychology, 21, 677-693. https://doi.org/10.1111/bjhp.12195

Roberto, K. A., \& Johnston, M. (1991). The impact of osteoporosis on the quality of informal relationships. Joumal of Gerontological Social Work, 16(1/2), 179-193. https://doi.org/10.1300/J083v16n01_13

Sambrook, P. N., Chen, J. S., Simpson, J. M., \& March, L. M. (2010). Impact of adverse news media on prescriptions for osteoporosis: Effect on fractures and mortality. The Medical Journal of Australia, 193(3), 154-156.

SBU. (2017). Behandling av armfraktur hos äldre. En systematisk översikt och utvärdering av medicinska, hälsoekonomiska, sociala och etiska aspekter. Stockholm: Statens beredning för medicinsk utvärdering (SBU); 2017. SBU-rapport nr 262/. (The Swedish Agency for Health Technology Assessment and Assessment of Social Services).

Svejme, O. (2013). Risk factors for bone fragility and fracture in postmenopausal women. Doctoral thesis. Clinical and Molecular Osteoporosis Research Unit, Clinical Sciences, 


\section{Macrothink \\ International Journal of Social Work \\ ISSN 2332-7278 2018, Vol. 5, No. 1}

Malmö: Skåne University Hospital, Lund University.

Svensson, H. K., Olofsson, E. H., Karlsson, J., Hansson, T., \& Olsson, L.-E. (2016). A painful, never ending story: older women's experiences of living with an osteoporotic vertebral compression fracture. Osteoporosis International, 27, 1729-1736. https://doi.org/10.1007/s00198-015-3445-y

Svensson, H. K., Olsson, L.-E., Hansson, T., Karlsson, J., \& Hansson-Olofsson, E. (2017). The effects of person-centered or other supportive interventions in older women with osteoporotic vertebral compression fractures: A systematic review of the literature. Osteoporosis International, 28, 2521-2540. https://doi.org/10.1007/s00198-017-4099-8

Sweden. (1992). Act (1992:1574) on housing adaptation (Lag om bostadsanpassningsbidrag m.m.).

The Act concerning Support and Service for Persons with Certain Functional Impairment (LSS), 1993:387. Lag om stöd och service till vissa funktionshindrade.

The Social Service Act (SoL), 2001:453. Socialtjänstlag.

The National Board of Health and Welfare. (2014). Legitimation för kuratorer inom hälsooch sjukvarrd. Stockholm: The National Board of Health and Welfare.

Wilson, S., Sharp, C. A., \& Davie, M. W. J. (2012). Health-related quality of life in patients with osteoporosis in the absence of vertebral fracture: A systematic review. Osteoporosis International, 23(12), 2749-2768. https://doi.org/10.1007/s00198-012-2050-6

\section{Copyright Disclaimer}

Copyright reserved by the author(s).

This article is an open-access article distributed under the terms and conditions of the Creative Commons Attribution license (http://creativecommons.org/licenses/by/3.0/). 